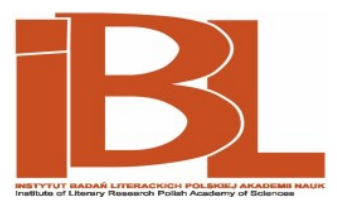

\title{
F5: Refreshing Philology
}

Maciej Maryl 


\section{F5: Refreshing Philology ${ }^{1}$}

DOI: 10.18318/td.2015.en.1.5

\begin{abstract}
"Digital Humanities involves the use of computers, the internet and related technologies to enable the creation and sharing of humanities scholarship in ways not possible in traditional humanities practice. Digital Humanities challenge the traditional understanding of the $\mathrm{Hu}$ manities by fostering interdisciplinary collaborations and providing new perspectives on the objects of humanistic inquiry"2.
\end{abstract}

$\mathbf{T}$ hat is the official definition from the whatisdigitalhumanities.com website; one of five hundred. And now we punch $\mathrm{F}_{5}$ (refresh website) and a new definition appears on our screens... Created by Jason Heppler, the website contains statements by participants of the Day of $D H$ from the years 2009-2012. Every time we visit the site

1 I employ the concept of Grzegorz Kurek in the title of this essay, which he designed as the name for an overview of contemporary "genre cinema", which I hope will take place one day. This article was first published as a foreword to the issue 4/2014 of Teksty Drugie, entitled New (?) Philology. The description of the issue's content, which constituted the second part of the Polish text, was omitted.

2 Jason Boyd (definition without a title) What is digital humanities, ed. J. Heppler, http://whatisdigitalhumanities.com/, accessed: 04.01.2014.
The article was written in the course of the project Blog jako nowa forma piśmiennictwa multimedialnego, founded from the means provided by the National Science Center on the basis of decision no. DEC-2011/03/N/ $\mathrm{HS}_{2} / 06232$.

Maciej Maryl - Ph.D., assistant professor and Deputy Director of the Institute of Literary Research of the Polish Academy of Sciences; founding head of the Digital Humanities Centre at the Institute of Literary Research of the Polish Academy of Sciences. Literary scholar, sociologist, and translator. $\mathrm{He}$ recently published a book on literary life on the Internet (in Polish). More information and publications: http:// maryl.org/ Contact: Maciej.Maryl@ibl. waw.pl

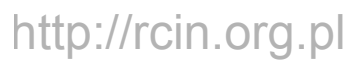


a different definition appears, which is supposed to be a sign, and an example, of emerging research field's ambiguity.

\section{F5}

Is digital humanities truly some kind of a new approach, a research current, or a discipline? If that is the case, as the above-mentioned Boyd wishes, then digital humanities have been cultivated at the offices of Second Texts for years, or at least since the beginning of the nineties, which is when the chief editor brought a big Macintosh machine from his scholarship residence at the Yale University. Later on, the optical fibers arrived at the gates of the Staszic Palace, and our editorial office went online. Then it was time for wi-fi, and the internal circulation of articles (this happened only a few years back) was seamlessly transferred to our email system. The last genuine letter, an April Fool's Day joke typed out on a typewriter, was received by us in 2013. And today? Today we keep our files in the cloud, and we use software designed for teamwork. Our printer collects dust, and is used only for its built-in scanner. We sit at our editorial staff meetings with tablets... Are these elements of digital humanities? We may be on to something if we were to recall numerous thinkers who make us realize how various writing technologies influence the way we think ${ }^{3}$.

\section{F5}

Digital humanities is the refreshed humanities. "Digital" makes it appealing (if not: "trendy"). It makes humanities seem fresh, mysterious (not everyone, after all, is an expert in the digital), or even "geeky". "Digital" means "new". The digital is sexy. Gregory Crane, a historian of antiquity and one of the pioneers of digital humanities (as the chief editor of Perseus Digital Library among other things) asks pertinently why we never speak of digital physicists, digital biologists, or (this phrase is arguably the best one) digital mathematicians ${ }^{4}$. The answer is simple - new, digital methods have become so embedded in those disciplines that it is impossible to separate one from the other. From that perspective, "Digital humanities" is a pleonasm, because everything we do is, to an extent, digital. Writing in a text editor, copy-paste, undo, redo, search... every such operation requires digital technology in which - whether we like it or not - we are completely immersed.

3 See Second Texts, 3 (2014).

4 A statement made at a conference (Digital) Humanities Revisited (Hannover, 5-7 December, 2013). 


\section{F5}

One can still go away, hide with a book somewhere in the mountains without any reception, without a phone, or email access. We can try to reject novelties, read only printed works, and write in a notebook... We can even try to limit our computer use to word processing and e-mails (no apps and cat pictures!). We can reject all of that, but it will always and forever be an escape FROM. It has become impossible to practice science in an analog.

\section{F5}

Digital humanities is not (only) about researching the "digital". This is not a discipline, nor a research current, but rather a movement or a collection of values common to researchers of various disciplines of humanities. However, opinions differ $\left(\mathrm{F}_{5}\right)$. For example, Piotr Celiński situates the "digital turn" next to other turns (linguistic, visual, postmodern, post-humanist), while treating it as the digitalization of the researcher's workshop, which is rather - in my opinion - a question from the sphere of meta-methodology of humanist sciences ${ }^{5}$. Put simply, I cannot see any major change in the research approach (a "turn" should assume such a change), but rather an evolution of methodology. Digital humanities does not require a rejection of the prevailing methods, approaches, state of knowledge, but are based on practicing research in a completely (or maybe: "slightly") different way. Let the second part of the Companion to digital literary studies serve as the best example. It is significantly entitled Traditions and is dedicated to digital methods of conducting research by historians of literature of various periods ${ }^{6}$. On the other hand (the theme about which we will learn from other parts of that above-mentioned publication), we are concerned here with the examining of new forms of textuality (such as blogs, e-mails, websites) using traditional categories of literary studies (narration, authorship, reception, the represented world, the perfect reader...).

\section{F5}

Let us employ the methods of digital humanities to talk about them themselves. Below, you shall find a word cloud created using the wordle.net

5 Piotr Celiński, "Renesansowe korzenie cyfrowego zwrotu" ("Renaissance roots of the digital turn") in Zwrot cyfrowy w humanistyce. Internet/Nowe Media/Kultura 2.o. (Digital Turn in Humanities. Internet/New Media/Cultutre 2.0), ed. A. Radomski, R. Bomba, (Lublin: E-naukowiec, 2013), 13 .

6 Ray Siemens, Susan Schreibman, ed. A companion to digital literary studies, (Oxford: Blackwell, 2008), http://www.digitalhumanities.org/companionDLS/ (accessed 09.16.2013). 
platform, and composed of all definitions included on the whatisdigitalhumanities.com website (21.028 words). Words which appear more frequently are relatively bigger (popular words, such as conjunctions and over-represented ones - 'digital' and 'humanities' - have been removed, in order to avoid the upsetting of the scale of the remaining words).

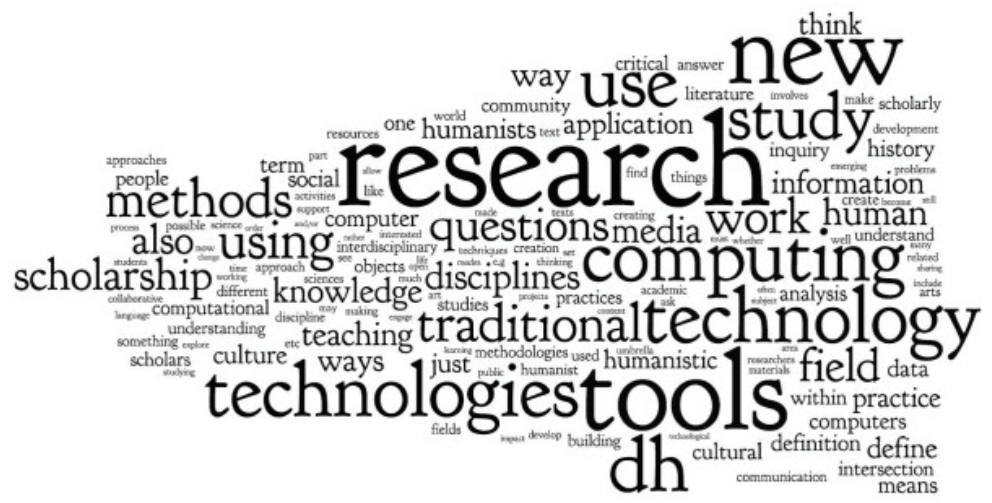

Terms which are central to the issue are fairly easy to spot: (new) research, methods, tools, technologies, and information... Digital humanities, I believe, is not about a specific set of research questions but rather about the method of scientific inquiry. In the introduction to this volume I will attempt to discuss a set of main assumptions of thus understood digital humanities in this way, which could be applicable to the field of literary studies ${ }^{\mathbf{7}}$.

\section{F5}

Tools. The key to understand digital humanities is their applicability, stemming from close cooperation with the applied sciences (social and information technology sciences). A text is treated not so much as an object of research, but as a tool enabling us to gather knowledge about itself and the broader cultural context. We are enabled to present previous versions or variants of a particular text, to conduct certain technical operations on it, using text editing software (for example, lexical analysis) andto tie that very work with its context materials via hyperlinks.

7 Apart from the source literature, I am dwelling on the experience drawn from two conferences: (Digital) Humanities Revisited (Hannover, 5-7 December 2013) and Achieving Impact. Socio-economic Sciences \& Humanities (SSH) in Horizon 2020 (Athens, 26-27 February 2014). 
Referring back to the three types of interest in a given text suggested by Ryszard Nycz - working with a text (hermeneutics), on the text (philological analysis), and by means of the text (text as a field for meaning-making processes) - we would be facing the latter type in this case ${ }^{\mathbf{8}}$. The metaphor of a "text as a laboratory" developed by Nycz finds its embodiment in the work of digital editors (for example, by Jerome McGann), or creators of collections (for example, the Curarium 9 project) -cultural artifacts become objects of the recipient's manipulation. Specifically, we are talking here about the so-called second wave of digitalization, in which digitized heritage becomes an object of further transformations performed using software. Only in such circumstances can one say that digitalization serves a different purpose than simple storage, and the provision of access to the facsimiles of a text; only then texts become fully digital. A deep level convergence of materials is involved in that process - today, we are able to transform texts and images in a similar manner as the analyses of Manovich, referred to below, show. A prime expression of that process would be the new incarnation of the digital library of Polona, which was turned from a collection of scans, which were difficult to search through, into a research tool. Tools become our research infrastructure, which requires continuous updates and maintenance ${ }^{10}$. The concept of "long-term research" acquires a new meaning - it is no longer only about finishing a project (for example, a dictionary), but about enabling it to be regularly updated and to make it accessible within the next ten, twenty, thirty years in a perpetually changing digital world.

\section{F5}

Data. Texts become tools, and information they carry becomes data. New tools bring new challenges to the research process: texts should be processed according to some international standards for meta-data (e.g. the Text Encoding Initiative), so they could be later compared and analysed together. The large amount of data provokes researchers to reach out for quantitative methods from other disciplines. Because of that, the very practice of "reading" acquires a new meaning:

8 Ryszard Nycz, "W stronę humanistyki innowacyjnej: tekst jako laboratorium. Tradycje, hipotezy, propozycje" ("Towards innovative humanities: text as a laboratory. Traditional hypotheses, proposoals"), Second Texts, 1-2 (2013): 249.

9 See http://www.curarium.com/

10 See the conclusions of the report by the European Science Foundation - Research Infrastructures in the Digital Humanities, September 2011, http://www.esf.org/fileadmin/Public_documents/Publications/spb42_RI_DigitalHumanities.pdf, (accessed 04.07.2014). 
Statistical and quantitative methods of analysis have brought close reading of texts (stylometrics and genre analysis, collation, comparison of versions for author attribution or usage patterns) into dialogue with distant reading (the crunching of large quantities of information across a corpus of textual data or its metadata) ${ }^{\mathbf{1 1}}$.

Although close reading in Polish literary studies is understood literally as "attentive reading", a proxemic reference is incredibly important here, and the difference between "close" reading, focused on specific words and sentences, and "distant" reading - performed from a higher plane, discovering relations between different texts, or collections (corpora) of texts - in particular ${ }^{\mathbf{1 2}}$.

The same applies to the meta-data of literary studies. A "tool-oriented" approach leads to a change of status of traditional forms of auxiliary research tools, such as dictionary or bibliography, which not only facilitates research, but can be also used to conduct it. Let us mention as an example this year's project of the IBL PAN, funded by the National Program for the Development of Humanities - "The Polish Literary Bibliography (PBL) - a knowledge lab on contemporary Polish culture". The name itself suggests a change in perspective. It is no longer about a source of bibliographic listings, but about a tool which will enable us to compare data of the period covered by PBL and other, secondary bibliographies (dating back to 1939). Researchers will be able to compare entries, and answer research questions ranging from the history of literary life, or sociology of reception (for example, the number of reviews of particular works, connections between selected writers, chronology of interest in a given work, etc.). In the perspective of things to come, such an attitude will influence the research process itself. I am thinking about the entire problem area of Big Data and the circumstances in which researchers should be able to reject the choosing of a single sample, and work on the entire available population instead. In the case of literary studies, this could mean further appreciation of the so-called lowbrow literature (popular, mass, perpound, pulp literature...), since the research process will be able to encompass all texts from a given time period ${ }^{\mathbf{1 3}}$.

Anne Burdick, et al. Digital Humanities, (Cambridge: The MIT Press, 2012), 18.

12 See Franco Moretti, Distant Reading, (London: Verso, 2013).

As an example let us mention semantic research conducted on about 3000 British novels from the period between 1785-1900. See Ryan Heuser and Long Le-Khac "A Quantitative Literary History of 2,958 Nineteenth-Century British Novels: The Semantic Cohort Method" Literary Lab Pamphlet, 4, (Stanford: 2012). 


\section{F5}

Visualization. It is an important aspect of digital humanities understood as, on the one hand, a presentation of results (of, for example, stylometric statistical analyses), and on the other hand - as a tool for analyzing and exploring data ${ }^{14}$. In the second case, "cultural analytics" moves away from scientistic research model of social sciences (theory-hypothesis-verification-theory) for the sake of "explorative visualization". It is based on qualitative research conducted on large quantities of data. Research by Lev Manovich can serve as an example: elements such as the visualization of individual shots from Vertov's movies, a series of covers of Time magazine, or a comparison of photographs of New York and Tokyo posted on Instagram. It is important to highlight the fact that, according to this approach, visualization becomes a phenomenon at the intersection of the research process and new medi a art ${ }^{15}$.

\section{F5}

Laboratory. The way of conducting research in digital humanities is worth paying close attention to, particularly the building of interdisciplinary research teams that combine members of different disciplines: researchers of culture, statisticians, IT specialists, archivists and documentalists ${ }^{\mathbf{1 6}}$. It is not so much about creating a research team in order to solve a particular problem, but rather about developing a lasting collaboration in various interdisciplinary projects. This interdisciplinary character has a "practical" dimension as well - it is not concerned with asking questions that rest on the boundary between disciplines, but about searching for answers to discipline-specific questions using new tools, often requiring additional competences.

14 See D.A. Keim, et al. ed. Mastering the information age. Solving problems with visual analytics, (Bad Langensalza: Druckhaus Thomas Müntzer $\mathrm{GmbH}, 2010$ ), electronic version: http://www. vismaster.eu/wp-content/uploads/2010/11/VisMaster-book- -lowres.pdf (accessed 04.07.2014). See Michał. B. Paradowski "Wizualizacja danych - dużo więcej niż prezentacja" ("Visualizing data - more than presentation") and "Dekalog analityka danych i infografika - quid, cur, quomodo" ("Data analyst and info-graphic designer Decalogue: quid, cur, quomodo) in M. Kluza, ed. Wizualizacja wiedzy. Od Biblia Pauperum do hipertekstu, (Lublin: Portal Wiedza i Edukacja, 2011).

15 See Radosław Bomba, 3 February 2013, the article "Eksperymentalna wizualizacja. Połączenie nauki i sztuki" Bomba.blog, http://radoslawbomba.umcs.lublin.pl/archives/1598 (accessed 04.06.2014).

16 We could point to Stanford Literary Lab, Trope Tank at MIT, or MetaLab at Harvard. 


\section{F5}

New forms of scientific communication and open scholarship. Another important characteristic of digital humanities is its insistence on deformalizing forms of scientific expression (that is, broadening the scholarly discourse with genres not present in it before), adjusting them to the new media facilities, and making them accessible to a wide audience. Organizing THATCamps (The Humanities and Technology Camp) - or non-conferences - is a part of that effort. They allow showcasing projects to everyone who works with digital media: researchers and practitioners (including artists). The main goal of these meetings is to popularize research and integrate the community.

Being a digital humanist is often connected with one's increased visibility on the web by means of publishing short popularizing texts on research blogs, or specialized websites, putting one's own texts in various repositories (preprints and post-prints of publications, conference presentations, research reports), as well as building multimedia narrations ${ }^{\mathbf{1 7}}$. Digital humanists (even though such classification seems to be singling out that particular group from among other humanists... I mean researchers employing digital methods in a broad sense) also make the tools they are using accessible - they publish lists of their tools, along with user's manuals, give access to data which was used for the analysis, or specific lines of code they have written, which add certain functions to existing, freeware software ${ }^{\mathbf{1 8}}$. However, we should remember that initiatives of this kind constitute an avant-garde in humanities, and are still not reflected in employee evaluation systems used by administrative boards, which certainly negatively influences the popularity of practices aiming at popularizing scientific knowledge ${ }^{19}$. As a result, we are faced with a paradoxical situation where it is far more "advantageous" to publish a text in a paper conference monograph with a small circulation, than it is to post it on a website (even on a reviewed one). Monographs are, of course, a basic form of research expression in humanities. However, they do not need to be made accessible in their printed form exclusively, which greatly limits their range.

17 Andrzej Radomski, "Digital storytelling. Kilka słów o wizualizacji wiedzy w humanistyce" ("Digital storytelling. Some remarks on the visualization of knowledge in the humanities") in Zwrot cyfrowy w humanistyce. Internet - Nowe Media - Kultura 2.o, ed. Andrzej Radomski and Radosław Bomba (Lublin: e-naukowiec, 2013).

18 See, for example: http://programminghistorian.org/, http://www.clementlevallois.net/, http://lab.so- ftwarestudies.com/p/software-for-digital-humanities.html.

19 See also: Radosław Bomba "Narzędzia cyfrowe jako wyznacznik nowego paradygmatu badań humanistycznych" ("Digital tools as markers if new research paradigm in humanities") in Zwrot cyfrowy w humanistyce, 66. 
It should be emphasized that the digital environment in the humanities is often connected to postulates concerning open access to the scientific knowledge, licensing and opening archives. Let us mention in passing that Second Texts sympathize with those postulates, and as you are reading these words, the archival issues of our periodical (excluding six of the latest ones) are already accessible for free in the bibliographical database of humanist and social periodicals BazHum ${ }^{20}$ as well as at the repository of the Institute of Literary Research of the Polish Academy of Sciences ${ }^{\mathbf{2 1}}$ (you are cordially invited to consult them).

\section{F5}

The new role of the researcher. Digital humanists situate themselves in a space between two worlds - scientific traditions of the humanities and a new, dynamically developing digital culture. Therefore the task of researchers is to understand both worlds and mediate between them, while transmitting ideas and viewpoints (in both directions). An example of such actions directed at researchers could be the above-mentioned divulgation of postulates about the open access to scientific content, and in a reverse direction - teaching the rudiments of the standards of editing to people uploading literary texts online. Viktor Mayer-Schönberger, the author of a book on Big Data, even defines this new kind of researcher as a data scientist:

The data scientist will need a multidisciplinary background that spans math and statistics, to computer science, design and the humanities. This is because one needs to be fluent in the language of data - how to run regression models and double-tailed T tests. But also possess coding skills to write programs to scrap data, clean data, or simply collect data. Then, one needs to eye of a designer to present the data visually. And storytelling skills to have the data reveal a narrative. Finally, one needs a deep sense of humanity - to ensure we are not beguiled by data's false charms, and we keep our common sense amid the spreadsheets ${ }^{22}$.

20 http://bazhum.pl/bib/journal/302/

21 http://rcin.org.pl/publication/63380

22 Niaz Uddin, Viktor Mayer-Schönberger: Big Data revolution, eTalks, http://etalks.me/viktormay-er-schonberger-big-data-revolution/, 03.31.2013 (accessed 04.06.2014). 
A data scientist, curator, corpus editor ${ }^{23}$ - the range of digital researchers' roles not only reaches beyond the boundaries of a discipline, but also greatly broadens the area of activities which heretofore were reserved for researchers.

\section{F5}

The audience. On the basis of the characteristics of digital humanities that were discussed here we may clearly infer the very last question that I would like to point our attention to - the broadening and change of the role played by the audiences. One could say that as a result of new technologies for scientific communications we could apply "the long tail" thesis, which assumes that Internet sales are revolutionized by access to virtually unlimited variety of cultural goods, allowing producers to profit from non-hit products, since they can make all of them accessible at once, but with minimal operational $\operatorname{costs}^{24}$. The accessibility of knowledge, and the above-mentioned new forms of scientific communication (including the open access to texts) facilitate easier access for the audience interested in particular scientific inquiries, even the less popular ones. The role of the recipients changes as well. They not only familiarize themselves with the results of research, but also take advantage of tools created by us. This allows the authors of the Digital_Humanities (text)book to develop their vision of omnipresent science (ubiquitous scholarship), "marked by an ethic of collaboration and interconnection on levels that move (almost effortlessly) between the global and the local, the library and the public square, the pen and the smartphone, the millennia-long histories of humankind and the real-time feeds of the now".25 The role of researchers is to work for a society that holds knowledge as its foundation, because it is right now when that phrase ceases to be an empty slogan.

\section{F5}

I am writing here about the digital humanities as a form of refreshing philology. This refreshing has no pejorative character (it does not stand for a ground-up "renovation", for example), nor is it overtly positive (I am far from

23 Gregory Crane, David Bamman and Alison Jones "ePhilology: when the books talk to their readers" in A companion to digital literary studies.

24 Chris Anderson, Długi ogon. Ekonomia przyszłości - każdy konsument ma głos, trans. B. Ludwiczak, (The Long Tail: Why the Future of Business Is Selling Less of More), (Poznań: Media Rodzina, 2008).

Burdick, et al. Digital Humanities, 60. 
uncritical enthusiasm). I believe that these changes support the research work of a philologist, but do not alter its purpose, which is reading a culture through its texts. While I write this brief description I begin to lose my confidence as to what those distinguishing elements of digital humanities (as compared to humanities as such) should be. After all, we are digital humanists, both as the creators of new tools and digital collections, as well as by virtue of using them. I rub my eyes ( $\left.\mathrm{F}_{5}\right)$ and still cannot see any major differences. Digital humanities is a scientific lifestyle, in which we all partake.

Translation:Jan Pytalski 